\title{
Physical Characteristic of Purple Sweet Potato (Ipomoea batatas L.) Modified Starch with Ultrasonication Method
}

\author{
Ira Gusti Riani ${ }^{1}$, Nura Malahayati ${ }^{2 *}$, Tri Wardani Widowati ${ }^{2}$, Merynda Indriyani Syafutri ${ }^{2}$
}

\author{
${ }^{1}$ Agribusiness Master Program, Faculty of Agriculture, Sriwijaya University, Jl. Masjid Al Gazali, Bukit Lama, Kec. Ilir Bar. I, Kota Palembang, \\ Sumatera Selatan 30128, Indonesia \\ ${ }^{2}$ Agricultural Product Technology Study Program, Faculty of Agriculture, Sriwijaya University, Jl. Masjid Al Gazali, Bukit Lama, Kec. Ilir Bar. I, Kota \\ Palembang, Sumatera Selatan 30128, Indonesia
}

DOI: $10.36347 /$ sjet.2020.v08i04.001

| Received: 21.03.2020 | Accepted: 30.03.2020 | Published: 07.04.2020

*Corresponding author: Nura Malahayati

Abstract

Original Research Article

This research was aimed to determine physical characteristic of purple sweet potato starch with ultrasonication method. Purple sweet potato starch was extracted using conventional method. The research used a Factorial Completely Randomized Design with three factors and each treatment was repeated three times. The factors were starch liquid ratio $(1: 1,2: 1)$, sonication time $(15,30,45$ minutes $)$ and sonication temperature $\left(30,40,50^{\circ} \mathrm{C}\right)$. The investigated parameters were bulk density, swelling power, solubility, water adsorption index, and viscosity. The result showed that solid liquid ratio of purple sweet potato starch and ultrasonication temperature had significant effect on bulk density, swelling power, solubility, water adsorption index, and viscosity. Interaction of solid liquid ratio and sonication time had significant effect on bulk density and viscosity. The interaction of the three factors had significant effect on bulk density only. Based on the lowest bulk density, the best treatment of this research was modified purple sweet potato starch with solid liquid ratio $1: 1$ on ultrasonication temperature $30^{\circ} \mathrm{C}$ at 15 minutes with swelling power $15,48 \%$, solubility $26,17 \%$, water absorption index $101,38 \%$, and water content $8,29 \%$.

Keywords: Purple sweet potato, modified starch, ultrasonication.

Copyright @ 2020: This is an open-access article distributed under the terms of the Creative Commons Attribution license which permits unrestricted use, distribution, and reproduction in any medium for non-commercial use (NonCommercial, or CC-BY-NC) provided the original author and source are credited.

\section{INTRODUCTION}

Indonesia has various types of potential tubers as a food diversification material. Food diversification is currently considered as the most rational way to solve food consumptions problems (especially carbohydrate sources). Tubers generally have a more affordable price so it is widely used for carbohydrate replacement food. Tubers are easily cultivated so that tuber production is relatively large. One of local tuber resources in Indonesia is purple sweet potato (Ipomoea batatas L.). Sweet potato production in Indonesia in 2016 was 18.54 tons/ha and productivity obtained $4.83 \%$ [1]. Purple sweet potato contains of carbohydrates $(27.9 \%)$, protein $(1.8 \%)$, fat $(0.7 \%)$, vitamins $(0.02 \%)$, minerals $(0,08 \%)$, crude fiber (1.2\%), and moisture (68.5\%) [2]. Moreover, purple sweet potato has higher amylose content than cassava, equal to $33.85 \%$ [3]. It makes the purple sweet potato tastes sweeter. Sweet potato can save sugar by $20 \%$ compared to flour [4].

Purple sweet potato is rich source of starch. The starch has been used as raw material for processed tuber-based products. However, the use of purple sweet potato starch as a native starch often encountered processing problems since it has limitations such as instability in high temperature, weak shear force, required a long time of processing, needed high energy, and too sticky $[5,6]$. A native purple sweet potato starch is not appropriate to be applied to food product that recently has high demand. So, modification of native starch has to be done.

Starch modification is an alternative that can be used to overcome the limitations of the physical and chemical properties of starch. The purpose of modified starch is to change the physicochemical properties of native starch by breaking the structure of the molecule and rearranging it to form a structure so it has better physical and chemical properties. Physical modification of starch is considered easier, simpler, and safer than that of chemical modification because it does not leave residues [7].

Ultrasonication is a physical modification of starch using ultrasonic waves with a frequency of 20 to $100 \mathrm{kHz}$. The technique gives a significant effect in 
accelerating various chemical and physical processes [8]. The physicochemical changes in ultrasonication are affected by prepared dispersion, ultrasound power and frequency, time and temperature of modification [9].

The effect of ultrasonication on purple sweet potato starch modification has not been studied. Therefore, this study is aimed to examine the effect of different starch liquid ratio, time and temperature of sonication on physical properties of sweet potato purple starch.

\section{EXPERIMENTAL SECTION RESEARCH MATERIALS}

The sample in this study was sweet potato purple (Ipomoea batatas L.) obtained from Padang Selasa traditional market in Palembang City, South Sumatera Province, Indonesia.

\section{Sample Preparation \\ Extraction of Sweet Purple Potato Starch}

Fresh tubers were washed, manually peeled, and were cut into small pieces $(1 \mathrm{~cm} \times 1 \mathrm{~cm} \mathrm{x} 1 \mathrm{~cm})$. Fresh tubers then dipped in water containing $10 \%$ salt for 12 hours with $1: 1(\mathrm{w} / \mathrm{v})$ of water. Diced sample was wet milled at high speed (18000 rpm) in a blender with 1:1 w/v of tap water for 2 minutes and filtered through a gauze cloth. Suspension was kept overnight for settling of starch. The supernatant was decanted, and the settled residue was further purified with repeated suspension in tap water $(1: 4 \mathrm{v} / \mathrm{v})$ followed by the settling for 12 hours. The purified starch was dried at $50^{\circ} \mathrm{C}$ for 6 hours, then sieved through 80 mesh, sealed, and packed for analysis.

\section{Ultrasonication Modified Starch}

Ultrasound treatment of sweet purple potato using a bath ultrasonic(Elmasonic $60 \mathrm{H}$ ) operating frequency on $37 \mathrm{kHz}$. The aqueous starch suspension obtained from the isolated sweet potato purple starch were treated with a constant ultrasound during different solid-liquid ratio $(1: 1,1: 2)$, sonication time $(15,30,45$ minutes), and sonication temperature $\left(30,40,50^{\circ} \mathrm{C}\right)$ using Beaker glass $250 \mathrm{~mL}$. The starch was dried at $50^{\circ} \mathrm{C}$ for 6 hours with oven (moisture content of 9$10 \%)$. The starch sieved through 80 mesh sieved and then stored at $4^{\circ} \mathrm{C}$ for analysis.

\section{Experimental Design and Statistical Analysis}

This research used a Factorial Completely Randomized Design with three factors. The factors were solid liquid ratio $(1: 1,2: 1)$, sonication time $(15$, 30,45 minutes), and sonication temperature $(30,40$, $50^{\circ} \mathrm{C}$ ). All treatments were replicated three times. Analysis of variance (ANOVA) were performed to determine the significant effect of the independent variables on the response variables. The treatments and their interactions were compared at $\mathrm{p}<0,05$ level using level significant difference method.

\section{Physicochemical Analysis \\ Bulk Density}

Bulk density was determined according to the method as followed [10]:

1. Sample was filled into a $250 \mathrm{~mL}$ of Beaker glass. Then, it was tapped gently several times.

2. Sample was weighed and results for bulk density were reported as $\mathrm{g} / \mathrm{mL}$.

\section{Swelling Power and Solubility}

Swelling power and solubility of the purple sweet potato starch was determined using method as followed [11]:

1. The starch about $0,1 \mathrm{~g}(\mathrm{~W})$ was weighed into 15 $\mathrm{mL}$ centrifuge tube, and $10 \mathrm{~mL}$ distilled water was added and mixing with vortex for 10 seconds.

2. The starch was heated in a water bath at $85^{\circ} \mathrm{C}$ for 30 minutes with intermittent shaking at 5, 15 and 20 minutes.

3. The starch was centrifuged at $2000 \mathrm{rpm}$ for 30 minutes then cooled at room temperature.

4. The supernatant was removed, and the remaining sediment in the tube was weighed $\left(\mathrm{W}_{1}\right)$.

5. The supernatant was dried to constant weight in a drying oven at $105^{\circ} \mathrm{C}\left(\mathrm{W}_{2}\right)$.

The following equation used to calculate the swelling power and solubility index as followed:

$$
\begin{gathered}
\text { Swelling power }(\%)=\frac{\text { weight of sedimented starch paste }(\mathrm{g})}{\text { weight of starch sample on dry basis }} \times 100 \% \\
\text { solubility index }(\%)=\frac{\mathrm{W}_{2}-\mathrm{W}_{1}}{\mathrm{~W}} \times 100 \%
\end{gathered}
$$

Where,

$$
\begin{aligned}
& \mathrm{W}_{2}-\mathrm{W}_{1}=\text { Weight of soluble starch }(\mathrm{g}) \\
& \mathrm{W}=\text { Weight of starch sample on dry basis }(\mathrm{g})
\end{aligned}
$$

\section{Water absorption index (WAI)}

Water absorption index (WAI) of the purple sweet potato starch was determined method as followed [12]:
1. Sample was determined by weighing $5 \mathrm{~g}$ into preweighed $50 \mathrm{~mL}$ centrifuge tubes and then distilled water $(25 \mathrm{~mL})$ was added to each tube.

2. The tubes vigorously shaken for 5 seconds to suspend the flour.

3. The suspension was allowed to solvate and swell for 20 minutes with intermittent shaking at 5, 10, 15 and 20 minutes. 
4. The samples were centrifuged at $1000 \mathrm{rpm}$ for 15 minutes after which the supernatant was decanted and pellet drained by touching with an adsorbentpaper towel.

5. Water absorption index was determined as the difference between the weight of the drained tube and the weight of the original empty tube/weight of dry sample.

$$
\text { WAI }(\%)=\frac{\text { Weight of soluble starch }}{\text { weight of dry sample }} \times 100 \%
$$

\section{Viscosity}

Apparent Viscosity of flour dispersions was determined using VT-4 as followed [13]:

1. Sample suspension was weighed about $10 \%$ in 250-mL Beaker glass.

2. Sample was measured using spindle at shear rate of $100 \mathrm{rpm}$ at $23 \pm 1^{\circ} \mathrm{C}$.

3. The readings were recorded after 30 seconds shearing time and results are reported in $\mathrm{mPas}$.

\section{RESULTS AND DISCUSSION Bulk Density}

The bulk density of ultrasound modified of purple sweet potato starch can be seen in Figure-1.

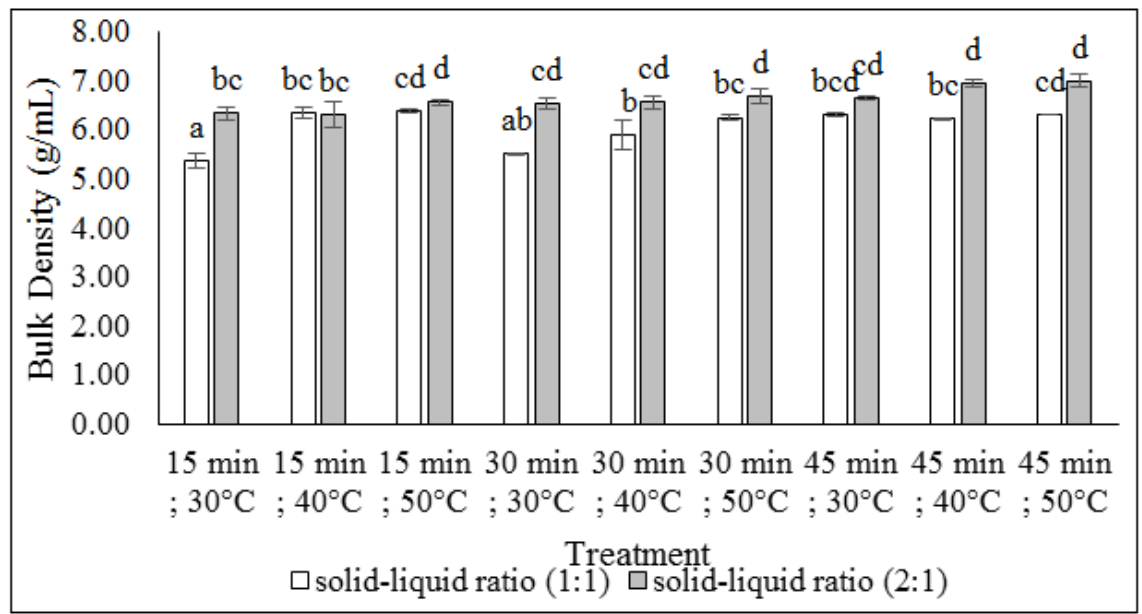

Fig-1: Bulk density graphic of ultrasound modified of purple sweet potato $\mathrm{starch}(\mathrm{g} / \mathrm{mL})$

The interaction of solid-liquid ratio starch, sonication time and sonication temperature had significantly effected on the bulk density of the samples. The higher liquid, the longer sonication time and the higher the temperature, the higher bulk density produced. High temperatures caused the reaction speed to be greater and size dispersions to become more uniform. High temperatures support particles aggregation. High temperatures resulted in rapid formation of crystal structures so that the particles aggregated into larger particle sizes [14]. Ultrasonic waves that are irradiated into solution caused collisions between particles. The molecules collided with each other and stretched so that the polymer bonds disrupted and caused the starch granules to become porous [15]. Starch granules increased porous with the longer ultrasound time and the higher the temperature used [16]. The longer particle collisions resulted in agglomeration. Agglomeration caused particles stick together to form small particles into bigger so the bulk density became larger.

Solid-liquid ratio starch (1:1) had a smaller bulk density than that ofsolid-liquid ratio starch $(2: 1)$.
This was solid-liquid ratio starch (1:1) contained more water added to the starch that facilitated more amylose to leached out and bonded with water due to the breaking of polymer bonds during ultrasonication treatment.The Power of cavitation caused the bubble collapse at high pressure. It caused the starch polymer chain to shift. Covalent bonding on starch granules broke because cavitation strength [17]. Furthermore, the amorphous part of starch can be damaged by ultrasonication treatment and resulted collisions between particles. This condition disrupted the regularity of the polymer bonds and the particle size became smaller that indicated the bulk density to be smaller due to more porous granular shape [18].

\section{Swelling Power}

Swelling power of purple sweet potato starch with ultrasonication modification can be seen in Figure2. The treatment which has the highest swelling power was a solid-liquid ratio $\operatorname{starch}(1: 1)$ using $30^{\circ} \mathrm{C}$ at 45 minutes sonication treatment $(16.28 \pm 1.727 \mathrm{~g} / \mathrm{g})$. The interaction between the three factors did not has significant effect on the swelling power of modified starch. 


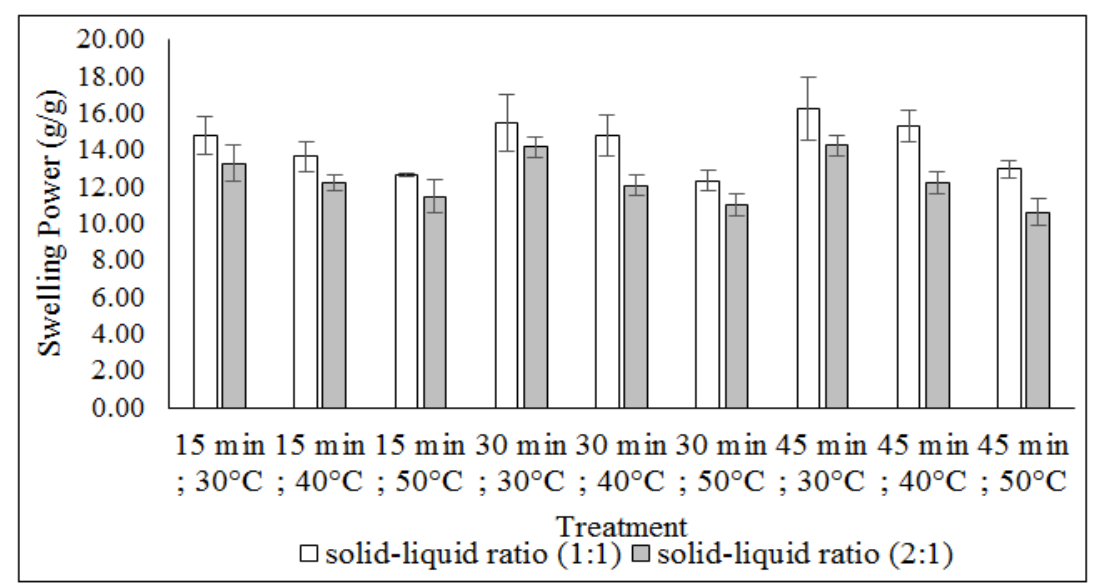

Fig-2: Swelling power (g/g) graphic of ultrasound modified of purple sweet potato starch

The comparison of starch and water showed significant effect on swelling power. Solid-liquid ratio starch $(1: 1)$ has a higher swelling power than that of $2: 1$. It was because higher water concentration caused more amylose leaching due to the ultrasonication process. Cavitation can damaged the structure of the molecule and the starch chain by disrupting covalent bonds. It caused the tissue of the starch granules loose. This condition occurred in the presence of water in the medium which functions as a conductor of force. More water caused the more loosens tissue of the starch granules, so that the swelling power becomes higher. Ultrasonication process was able to integrate the polymer bonds in starch. The ultrasonication method resulted in the formation of gas bubbles through the water as medium. The formation of bubbles in the suspension medium becomes the destroyed starch polymer chain. Due to the cavitation bubbles, water as a medium can be partially apparted into $\mathrm{OH}^{-}$and $\mathrm{H}^{+}$then diffused out of the surrounding liquid and reacted with dissolved molecules due to polymer degradation. The starch polymer chain has weakened due to the cavitation process so it caused easing the tissue and increase the swelling power of the starch [19].

Furthermore, the ultrasonication temperature has a significant effect on the resulting swelling power.
Higher temperature caused the swelling power to become lower. It was because ultrasonication caused amylose form due to the disruption of polymer bonds in starch. The ultrasonication treatment produces bubbles because the cavitation process was able to cause rearrangement of starch granules then break the polymer chain by destroyed covalent bonds [20]. At higher temperatures, bubbles will be produced simultaneously. High temperatures of sonication for a certain period of time can result in weak molecular bonds of intermolecular starch. The longer time caused the weak bond of granules starch and more sustainable [21]. Amylose will be separated from the bond so the swelling power is lower. The decrease in swelling power is followed by a decrease in amylose content. Higher temperatures caused amylose in starch to be lower. At higher temperatures, cavitation bubbles will easily form and they can break the bonds of amylose molecules so amylose can be damaged [22, 23].

\section{Solubility}

The solubility ofmodified purple sweet potato starch can be seen in Figure-3. The highest solubility values were found in the treatment solid-liquid ratio $\operatorname{starch}(1: 1), \quad$ ultrasonication time 45 minutes,ultrasonication temperature $30^{\circ} \mathrm{C} \quad(28,98 \quad \pm$ $1,81 \%)$.

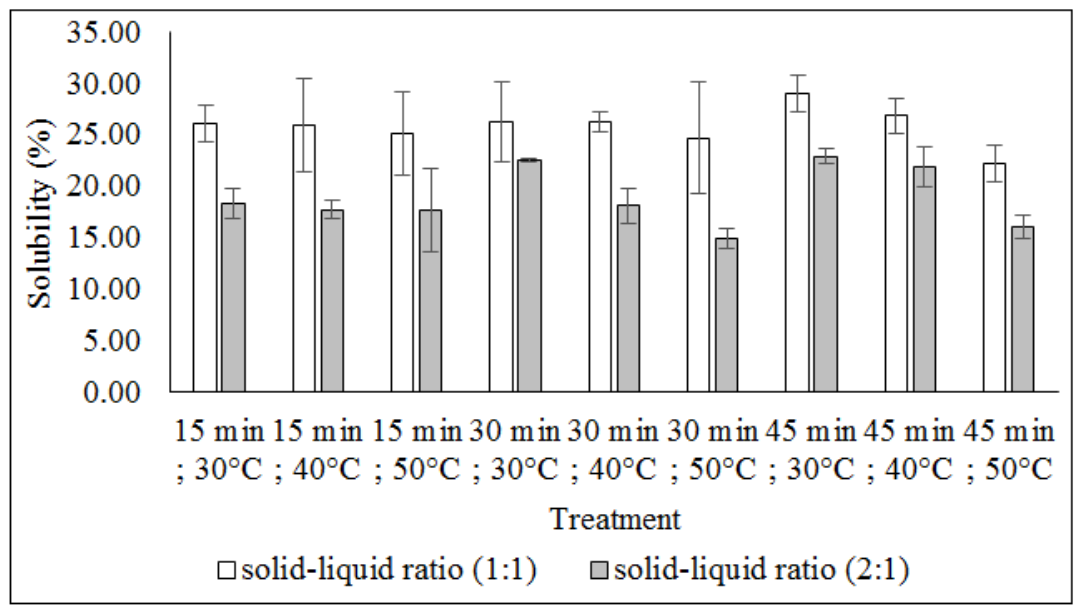

Fig-3: Solubility (\%) graphic of ultrasound modified of purple sweet potato starch 
Solid-liquid ratio starch and ultrasound temperature has significant effect for solubility starch. However, the interaction between the three factors did not have a significant effect on solubility. Solid-liquid ratio starch $(1: 1)$ had higher solubility value than that of solid-liquid ratio starch $(2: 1)$. It was because solidliquid ratio (1:1), has more water, facilitated more starch leaching out together with water than that of solid-liquid ratio $(2: 1)$. Ultrasonic treatment damaged the crystalline region and bonded between molecules. In the presence of ultrasonic strength, the molecular bonds in the starch granules are broken and degraded the granules. Ultrasonic weakens the molecular bonds in the particles and loosens the structure of the starch particles. In turns, the amylose dissolved into water so that the solubility was higher. More water addition will facilitate the starch out and leaching together with water [16].
The shorter sonication time resulted less molecular degradation and decreased solubility. Ultrasonication weakened the molecular bonds and the granules loosened and starch molecules dissolved easily. Due to ultrasound treatment, the granule is destroyed, resulting in precipitation of free water, breakage of starch chain caused reordering of chain segments [21]. The more water ratio and the longer sonication time caused more granules degradation so solubility increased.

\section{Water Absorption Index}

Water absorption index for modified purple sweet potato starch with ultrasonication modification can be seen in Figure-4. The highest water absorption index value was found in treatment of solid-liquid ratio starch (1:1), ultrasonication time 30 minutes, and ultrasonication temperature $50^{\circ} \mathrm{C}(116,67 \pm 9,775 \%)$.

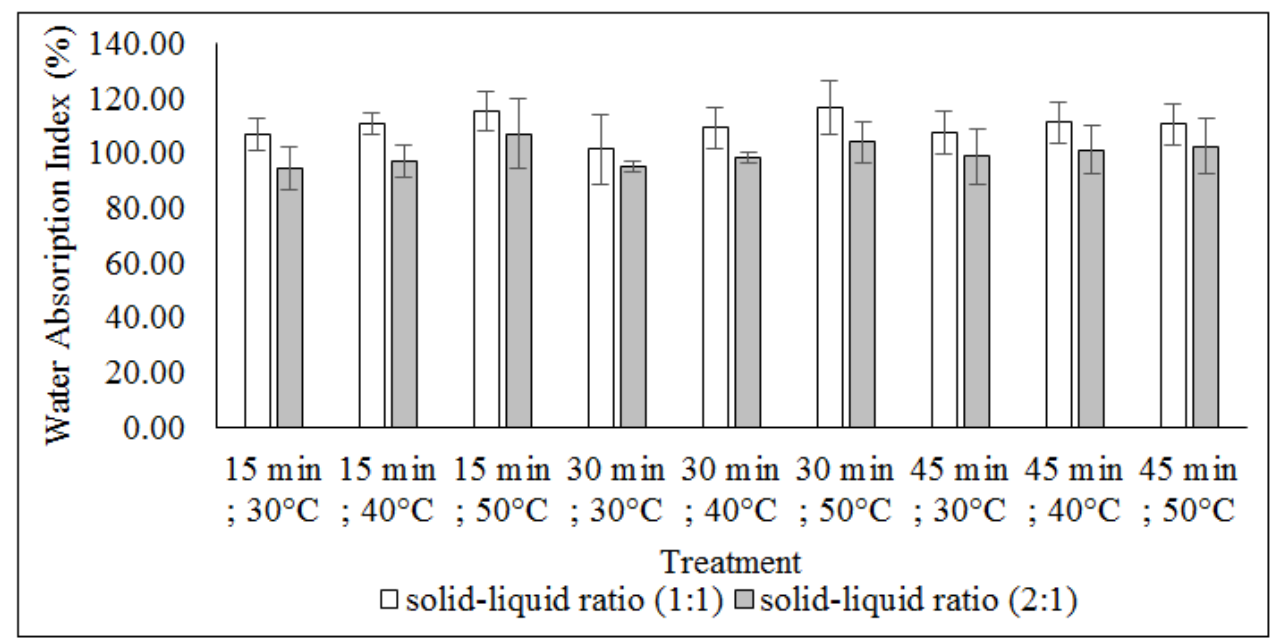

Fig-4: Water absroption index (\%) graphic of ultrasound modified of purple sweet potato starch

The interactions solid-liquid ratio starch, ultrasonication time and ultrasonication temperature did not show a significant effect on the water absorption index. However, solid-liquid ratio starch and ultrasonication temperature have significantly effected on water absorption index. Solid-liquid ratio starch (1:1) showed a higher water absorption index than that of solid-liquid ratio starch (2:1). The higher water absorption capacity due to ultrasonication facilitated the water into starch granules which caused higher water absorption [24].

Moreover, that cavitation process caused the granule matrix to become more porous due to the cavitation bubbles. During cavitation, the reactivity of the water increased and produced a high pressure which increased the diffusion of water into the starch granules, especially in the amorphous region [20]. Water also functions as a heat conductor and as a medium for cavitation. Disintegration of starch granules caused by cavitation forces can damage the structure of crystalline molecules and starch chains by disrupting covalent bonds. Cracked granules due to ultrasonication make granules tend to be more porous. More porous granules caused more water to be absorbed into the starch granules [25].

The longer the ultrasonication time and the higher the ultrasonication temperature caused the water absorption index increase. This was because of the cavitation process due to ultrasonic treatment. High temperature increased the vapor pressure then cavitation was easier to be occurred [26]. The cavitation process resulted in loosen of the tissue that caused the matrix to become more porous [20]. Cavitation destroyed crystalline area of starch due to reversible hydration of amorphous regions. It increased the hydrolysis of starch so more water was absorbed [27].

\section{Viscosity}

Viscosity of modified purple sweet potato starch with ultrasonication modification can be seen in Figure-5. The highest viscosity value was solid-liquid ratio $\operatorname{starch}(1: 1)$, ultrasonication time of 15 minutes, and ultrasonication temperature of $30^{\circ} \mathrm{C}(13,40 \pm 1,311$ mPas). 
The result showed that solid-liquid ratio starch and ultrasound temperature has a significant effect for viscosity. Moreover, the interaction between three factors did not has significant effect on viscosity. Solidliquid ratio starch (1:1) has higher viscosity than that of solid-liquid ratio starch $(2: 1)$.
The starch with a higher water ratio allowed to absorbed, it caused starch to become thicker [21]. The absorbed water was caused by the starch given ultrasonication treatment which had a more porous surface, it made easier to absorb water and affect the thickness [28]. Porous surface formed due to the ultrasonication process makes it easier for starch to absorb water so that the viscosity was higher.

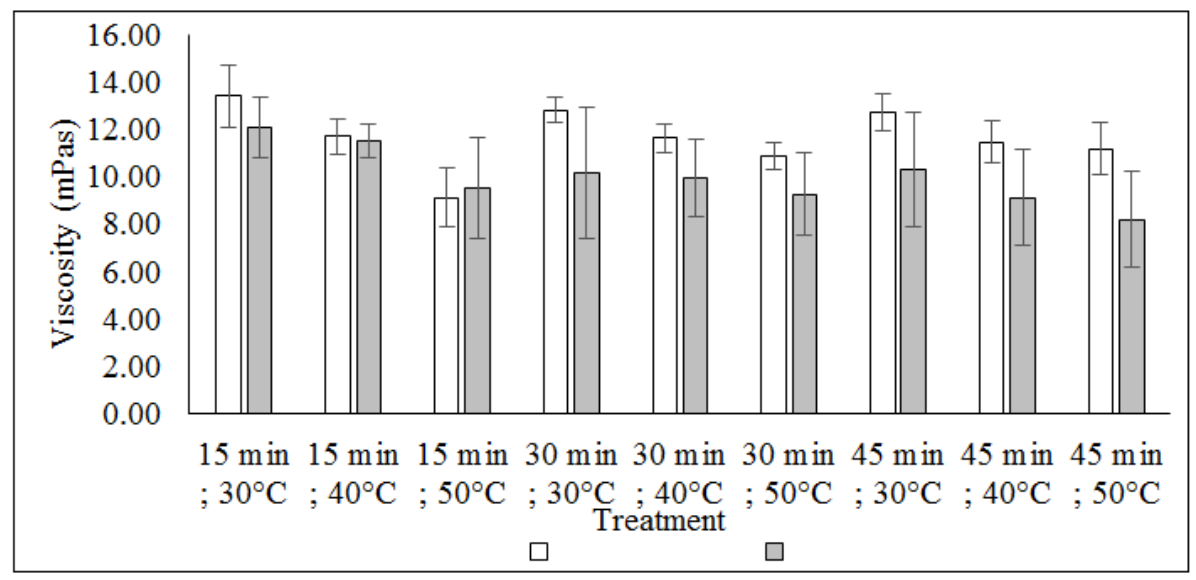

Fig-5: Viscosity (mPas) graphic of ultrasound modified of purple sweet potato starch

Water as a medium can support the tissue loose. The water was as a heat conductor during ultrasonic treatment. In addition, water functions as a conductor of heat so that it can help loosened tissue which caused more porous structure. If a granule was heated in an aqueous medium, the hydrogen bonds that maintain the starch structure become weakened so the granules absorbed water. The weakening of this bond was supported by the ultrasonication treatment. As a result of cavitation bubbles, the bonding of starch polymers disrupted; thus, it affected the change in polymer structure. Cavitation conditions with highintensity vibrations that cause noise due to the bursting of steam bubbles occured continuously [29]. Cavitation bubble is formed during ultrasound process can damage starch surface. This condition caused the surface of starch becomes more porous and more absorp water easily so the viscosity of starch was higher.

The lower ultrasound temperature causes higher starch viscosity. Fluid viscosity was greatly influenced by temperature; if the temperature risen, the gas viscosity increased; while the viscosity of the liquid decreased. The decreasing of viscosity was due to the breakdown of particles and granules into smaller sizes. The breakdown of particles into smaller granules was due to the ultrasonication treatment. A decreasing of viscosity indicated a decreasing in the number of particles that dissolved in solution after sonication. High strength ultrasonic waves were known to be able to damage cell walls or the surface of solid material [30].

\section{CONCLUSION}

The results of this study indicated that interaction of three factors (solid liquid ratio, ultrasonication temperature, and ultrasonication time) only has a significant effect on the bulk density of modified of purple sweet potato starch.The ultrasound modified starch contained bulk density of $0.5506 \pm 0.02 \mathrm{~g} / \mathrm{mL}$.

\section{REFERENCES}

1. Suwandi. Outlook sub sector food crop agricultural commodities: sweet potato. Ministry of Agriculture's data center and information system. Jakarta. 2016:7-9.

2. Muchtadi TR, Sugiyono. Food Science Laboratory Instructions. Bogor: Inter-University Center for Food and Nutrition University of Menistry of Environment and Forestry of Indonesia. 1992.

3. Polnaya F, Breemer R, Augustyn GH, Tuhumury, HCD. Physicochemical characteristic of sweet potato, cassava, taro and sago starch. Agrinimal. 2015;5(1):37-42.

4. Koswara S. Tuber processing technology Part 4 :Canna edulis Kerr. processing. Southeast Asian Food and Agricultural Science and Technology Center IPB. 2013.

5. Firgianti G, Sunyoto M. Physical and chemical characterization of purple sweet potato (Ipomoea batatas. L) prickly varieties to support the supply of raw sweet potato flour. National Seminar of UNS. 2018; 2(1): F104-F110.

6. Kusnandar F. Starch modification technology and its application in the food industry. Southeast 
Asian Food and Agricultural Science and Technology Center IPB. 2010.

7. Kaur B, Ariffin F, Bhat R, Karim A. Progress in Starch Modification in The Last Decade. Food Hydrocolloids. 2012;26:398-404.

8. Leong $\mathrm{T}$, Ashokkumar, Kentish S. The fundamental of power ultrasound. Acoustic Australia. 2011;39(2):54-63.

9. Zuo JY, Knoerzer K, Mawson R, Kenish S, and Ashollumar, M. 2009. The Pasting Properties Of Sonicated Waxy Rice Starch Suspensions. Ultrasonics Sonochemistry. 2009;(16):462-468.

10. Muchtadi TR, Sugiyono, Ayustaningwarno F. Food Science. Alfabeta. Bandung. 2010.

11. Senanayake S, Gunaratne A, Ranawera K, Bamunuarachchi A. Effect of heat moisture treatment conditions on swelling power and water soluble index of different cultivar of sweet potato (IpomeaBatatas L.) starch. Isrn Agronom. 2018: 1-4.

12. Onyango C, Mewa A, Mutahi, Okoth A. Effect of heat moisture treated cassava starch and amaranth malt on the quality of Sorghum-Cassava-Amaranth Bread. Journal Food Science. 2013; 7 (5): 80-86.

13. McCabe WL, Smith JC, Harriot P.Chemistry Technic Operation Part Four Translate by Jasfi E. Erlangga. Jakarta. 1987.

14. Wei, Ling Y, Chang. Characteristics of nano zinc oxide synthesized under ultrasonic condition. Physic chemistry and solids. 2008; 5(69): 688-692.

15. Moholkar VS, Rekveld S, Warmoeskerken. Modeling of the acoustic pressure fields and the distribution of the cavitation phenomena in a dual frequency sonic processor. Ultrasound. 2000;38: 666-670.

16. Zhang $\mathrm{H}, \mathrm{Li} \mathrm{M}$, Kun, Li, Zhu C.Effect of ultrasound pretreatment on physicochemical properties of corn starch. Advances in Engineering Research. 2018; (164): 572-576.

17. Singh N, Singh J, Kaur L, Sodhi NS, Gill BS. Morphological, thermal and rheological properties of starches from different botanical sources. Food Chemistry. 2003; 81: 219-231.

18. Ardiansyah N, and Maryanti E. The effect of addition of natural sulfur to synthesis of $\mathrm{ZnO}$ nanoparticles based on capping aren't water extract of sapindus rarak DC with sonochemical method. Gradien. 2014; 10 (2):1025-1028.

19. Czechowska, Biskup R, Rokita B, Lotfy S, Ulanski P, and Rosiak JM. Degradation of chitosan and starch by $360-\mathrm{kHz}$ ultrasound. Carbohydrate Polimer.2005; 60 (2): 175-184.

20. Jambrak AR, Herceg, Z, Subaric D, Babic J, Brncic M, Rimac, Brncic S, Bosiljkov TC, TripaloB, Gelo J. Ultrasound effect on physical properties of corn starch. Carbohydrate Polimer. 2010; 79: 91-100.

21. Krisnakumar T, Sajeev MS. Effect of ultrasound treatment on physicochemical and functional properties of cassava starch. International Journal of Current Microbiology and Applied Sciences. 2018; 7(10): 3122-3135.

22. Suslick S. Applications of ultrasoundto Materials Chemistry. MRS Bulletin. 1995; 29-34.

23. CaiX , Jiang Z, Zhang X. Effects of tip sonication parameters on liquid phase exfoliation of graphite into graphene nanoplatelets. Nanoscale research letters. 2018; 13 (241).

24. Manchun S, Nunthanid J, Limmatvapirat S, Sriamornsak P. Effect of ultrasonic treatment on physical properties of tapioca starch. Advanced Materials Research. 2012; 506: 294-297.

25. Ardhiyanti SD, Ahza AB, Faridah DN, Kusbiantoro B. Characteristic of modified rice flour by combination of microwave, ultrasonication with heat moisture treatments. Journal of Science and Food Industry. 2016; 27(2): 175-184.

26. Cravotto G, Cintas P. Handbook on Applications of Ultrasound: Sonochemistry for Sustainability. Florida (US): CRC Press. p33.

27. Chung KM, Moon TW, Kim H, Chun JK. Physicochemical properties of sonicated mung bean, potato and rice starches. Cereal chemistry. 2002;79(5): 631-633.

28. Carolina S, Almedia, Angela M. Physicochemical properties, modifications and applications of starches from different botanical sources. Food Science and Technology. 2015;35(2):215-236.

29. Delly J. Effect of temperature on cavitation at centrifugal pump blades. Dynamics Journal of Mechanical Engineering Scientific. 2009; 1(1): 21 27.

30. John F. Ultrasonic Cleaning : Fundamental Theory and Application. [online]. 2002 [cited 2009 August 01] Availbale from :URL:http://mrc.magicnet.co.il/data/MagicNetFile s/General//Ultrasonic\%20Cleaning.pdf. 